\title{
Performance of Blood culture, $\beta$-D-glucan and PCR for Diagnosis of Systemic Fungal Infection in Cancer Patients
}

\author{
Mohammed Elshaer*, Amina Abd El Aal, Ahmad Elewa, Noha El-Mashad \\ Clinical Pathology Department, Faculty of Medicine, Mansoura, Egypt \\ *Corresponding author: melshaer85@mans.edu.eg
}

Received April 08, 2019; Revised May 19, 2019; Accepted June 05, 2019

\begin{abstract}
Background and purpose: The incidence of systemic fungal infection has increased considerably in recent years. It is of greater concern because they are often misdiagnosed. The study aimed to assess the diagnostic performance of ELISA and Polymerase chain reaction versus the gold standard blood culture in diagnosing systemic fungal infection. Materials and Methods: The study included 70 cancer patients at the Mansoura University Oncology Center clinically suspected to suffer from systemic fungal infection. Blood samples were subjected to automated blood culture, antigen detection by ELISA and PCR for fungal DNA. Results: Considering the different methods used for diagnosis of systemic fungal infection, 19 patients were positive by blood culture, 36 patients were positive by ELISA and 32 patients were positive by PCR. Both $\beta$-D-glucan and PCR exhibited higher sensitivity, specificity and accuracy with higher NPV than PPV compared to the gold standard blood culture which lacks the desired sensitivity and specificity. Conclusion: Rapid diagnostic techniques such as ELISA and PCR offer an accurate and reproducible tool for early diagnosis and treatment of fungal pathogens.
\end{abstract}

Keywords: blood culture, fungi, enzyme-linked immunosorbent assay, polymerase chain reaction, systemic fungal infection

Cite This Article: Elshaer M, El Aal AA, Elewa A, and El-Mashad N, "Performance of Blood culture, $\beta$-D-glucan and PCR for diagnosis of Systemic Fungal Infection in Cancer Patients." American Journal of Microbiological Research, vol. 7, no. 3 (2019): 73-77. doi: 10.12691/ajmr-7-3-1.

\section{Introduction}

Systemic fungal infection is a serious cause of mortality and morbidity in immunocompromised patients, including hematological malignancy, transplant recipients, and those under intensive care or chemotherapy. Therefore, there is an urgent need for early and appropriate antifungal treatment [1]. Establishing a definite diagnosis of fungal infection in immunocompromised patients is particularly challenging and time consuming, but delayed initiation of antifungal treatment increases mortality [2].

New diagnostic approaches have been developed based on nonculture based methods, including antigen-based assays, metabolite detection and molecular detection of fungal DNA from body fluid samples which may allow early diagnosis and treatment of fungal infection [3]. $1,3-\beta$-D-glucan (BDG) is a component of the fungal cell wall that presents in many fungal species and therefore it should be considered as a pan-fungal detection method and a good indicator of systemic fungal infection, if detectable in blood or other normally sterile body fluids [4].

Molecular techniques, including DNA sequencing, microarrays, FISH and polymerase chain reaction (PCR), have been used for broad-range molecular detection assays. These techniques have become more available in many laboratories; allow identification of rare fungal species with a large database [5]. The aim of our study was to assess the diagnostic performance of ELISA and Polymerase chain reaction versus the gold standard blood culture in diagnosing systemic fungal infection.

\section{Material \& Methods}

\subsection{Study Locality and Duration}

This study was conducted at Mansoura University Oncology Center, Egypt over a period of one year to obtain a convenience sample of patients.

\subsection{Inclusion Criteria}

The study included 70 cancer patients with clinically suspected systemic fungal infection (all patients were undergoing intensive chemotherapy and presented with febrile neutropenia not responding to broad-spectrum antibiotics).

\subsection{Exclusion Criteria}

Patients receiving systemic antifungal drugs were excluded. 


\subsection{Sampling}

Venous blood was obtained by venipuncture under aseptic conditions then divided into the following:

- $20 \mathrm{ml}$ of blood immediately inoculated into two special blood culture bottle BacT/Alert FA vials (Biomérieux, USA).

- $3 \mathrm{ml}$ were put into plain vacutainer tube, left for 20 minutes at room temperature to clot, then centrifuged at $3000 \mathrm{rpm}$ for 5 minutes; the separated serum was used for beta d glucan assay by ELISA.

- $2 \mathrm{ml}$ were put into a sterile vacutainer (EDTA) containing tubes for genomic DNA extraction. Samples were kept frozen at $-70^{\circ} \mathrm{C}$ till performing DNA extraction.

\subsection{Methods}

- Automated blood culture using the BacT/Alert system (Biomérieux, USA) to detect early fungal growth and to exclude possible contamination.

- Enzyme-linked immunosorbent assay for 1,3- $\beta$-D-glucan in serum (Inovbio, China). The kit uses sandwich-ELISA as the principle. Standards or samples were added to the wells and combined to the specific antibody then horseradish Peroxidase (HRP) conjugated antibody specific for 1-3- $\beta-D$ glucan was added to each strip. The optical density (OD) was measured spectrophotometrically at a wavelength of $450 \mathrm{~nm}$.

- Detection of fungal DNA in whole blood samples by

\subsubsection{DNA Extraction}

Genomic DNA extraction from whole blood sample inoculated on EDTA supplemented tubes was carried out using DNA extraction Qiamp UCP Pure Pathogen mini kit (Qiagen, Germany). The kits will be used in accordance with the manufacturer's recommendations.

\subsubsection{PCR Amplification}

PCR amplification was performed using:

- Biorad Thermal cycler (Biorad, USA)

- DreamTaq Green PCR Master Mix.

- Pan-fungal primers targeting the ITS1 and ITS4 regions to generate a PCR product of $500 \mathrm{bp}$.

The used primers were $18 \mathrm{~S}$ forward primer 5'- ATTGGAGGGCAAGTCTGGTG-3' and 18S-reverse primer 5' CCGATCCCTAGTCGGCAT-3' (Sigma, USA). The Internal Transcribed Spacer (ITS) regions consist of highly preserved sequences of great importance for the identification of fungal genome in whole blood samples. Negative and positive control samples were used in every assay. Blood sample used as a negative control was obtained from a healthy volunteer. While positive control was prepared by mixing the blood sample obtained from a healthy volunteer with approximately $150 \mathrm{CFU}$ of Candida albicans in $500 \mathrm{ml}$ volume.

The cycling parameters include hot start denaturation at $95{ }^{\circ} \mathrm{C}$ for $5 \mathrm{~min}$, followed by denaturation at $95^{\circ} \mathrm{C}$ for $1 \mathrm{~min}$, annealing at $55^{\circ} \mathrm{C}$ for $1 \mathrm{~min}$, extension reaction at $72{ }^{\circ} \mathrm{C}$ for $1 \mathrm{~min}$ and a final extension at $72^{\circ} \mathrm{C}$ for $7 \mathrm{~min}$. The presence of specific PCR products will be detected using electrophoresis on a $1 \%$ agarose gel and staining with ethidium bromide.

The diagnostic performance of ELISA and PCR was compared to blood culture which is currently considered the gold standard technique for diagnosis of systemic fungal infection. The collected data were analyzed using SPSS Version 21 using appropriate statistical significance test.

\subsection{Ethical consideration}

The ethics committee of the Faculty of Medicine, Mansoura University, Egypt, approved this study (MD/16.01.42).

\section{Results}

Over a period of one year, blood samples were collected from 70 cancer patients with suspected systemic fungal infection. The majority of samples were obtained from female patients $(51.7 \% ; 48.3 \%$ from males $)$, with a mean age of $34.93 \pm 20.17 \mathrm{y}$ and $43.36 \pm 21.64 \mathrm{y}$ in males and females respectively.

Comparing the results of different methods used for the diagnosis of systemic fungal infection. In total, 45 patients were determined positive by at least 1 of the 3 techniques evaluated. 19 patients were positive by blood culture, 36 patients were positive by ELISA and 32 patients were positive by PCR (Table 1, Figure 1 - Figure 2).

Table 1. Diagnostic methods for systemic fungal infection $(n=70)$

\begin{tabular}{|c|c|c|c|}
\hline \multirow{2}{*}{ Result } & \multicolumn{3}{|c|}{ Diagnostic method } \\
\cline { 2 - 4 } & Blood culture & ELISA & PCR \\
\hline Positive & $19(27.1 \%)$ & $36(51.4 \%)$ & $32(45.7 \%)$ \\
\hline Negative & $51(72.9 \%)$ & $34(48.6 \%)$ & $38(54.3 \%)$ \\
\hline
\end{tabular}

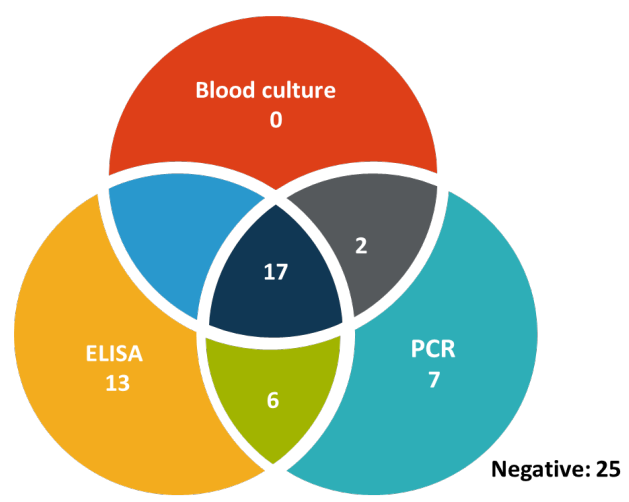

Figure 1. Venn diagram showing number of positive results in each combination of blood culture, ELISA and PCR $(\mathrm{n}=70)$

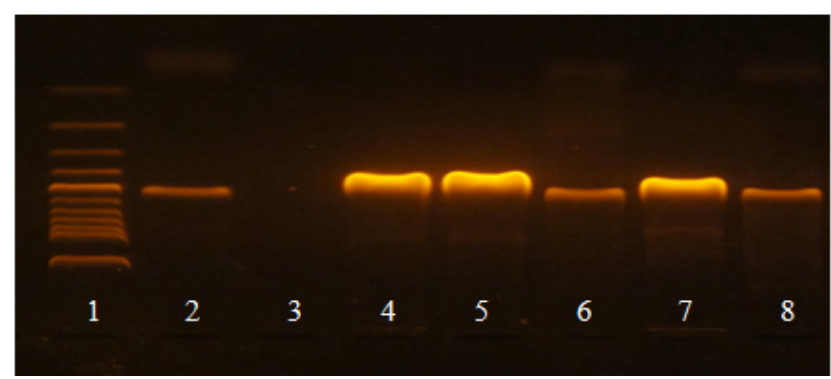

Figure 2. PCR analysis using Pan-fungal primer for internal transcribed spacer (ITS1) and (ITS4) regions, occasionally, 492 and $503 \mathrm{bp}$ amplified DNA products were obtained due to the highly variable internal transcribed spacer (ITS) regions, common in the general fungus genetic code

Lane 1: Molecular size marker (50-1500 bp), Lane 2: Positive control Lane 3: Negative case, Lane 4: Positive case Lane 5: Positive case, Lane 6: Positive case, Lane 7: Positive case, Lane 8: Positive case 
Table 2. Serum 1, 3- $\beta$-D-glucan by ELISA in comparison to blood culture $(n=70)$

\begin{tabular}{|c|c|c|c|c|c|c|c|c|c|c|c|}
\hline \multirow{3}{*}{$\begin{array}{l}\text { Blood culture } \\
\quad(n=70)\end{array}$} & \multicolumn{6}{|c|}{$\begin{array}{c}\text { ELISA } \\
(n=70)\end{array}$} & \multirow{3}{*}{$\begin{array}{c}\text { Sensitivity } \\
\%\end{array}$} & \multirow{3}{*}{$\begin{array}{c}\text { Specificity } \\
\%\end{array}$} & \multirow{3}{*}{$\begin{array}{c}\text { Accuracy } \\
\%\end{array}$} & \multirow{3}{*}{$\begin{array}{c}\text { PPV } \\
\%\end{array}$} & \multirow{3}{*}{$\begin{array}{c}\text { NPV } \\
\%\end{array}$} \\
\hline & \multicolumn{2}{|c|}{$+\mathrm{ve}$} & \multicolumn{2}{|c|}{-ve } & \multicolumn{2}{|c|}{ Total } & & & & & \\
\hline & No & $\%$ & No & $\%$ & No & $\%$ & & & & & \\
\hline$+v e$ & 17 & 24.3 & 2 & 2.8 & 19 & 27.1 & \multirow{3}{*}{89.5} & \multirow{3}{*}{62.8} & \multirow{3}{*}{70} & \multirow{3}{*}{47.2} & \multirow{3}{*}{94.1} \\
\hline -ve & 19 & 27.1 & 32 & 35.8 & 51 & 62.9 & & & & & \\
\hline Total & 36 & 51.4 & 34 & 48.6 & 70 & 100 & & & & & \\
\hline
\end{tabular}

Kappa-Value $=0.41$

$\%$ Agreement $=70 \%$

$\mathbf{P}-$ Value $=0.001 ; \mathbf{P}<0.05$ : significant $\mathbf{P}<0.01$ : highly significant

Kappa-Value: Strength of agreement Poor $<0.2$ Fair: 0.2-0.4 Moderate: 0.41-0.6 Good: 0.61-0.8 Very good: 0.81-1.0.

Table 3. Pan-fungal PCR in comparison to blood culture $(n=70)$

\begin{tabular}{|c|c|c|c|c|c|c|c|c|c|c|c|}
\hline \multirow{3}{*}{$\begin{array}{l}\text { Blood } \\
\text { culture } \\
(n=70)\end{array}$} & \multicolumn{6}{|c|}{ Pan-fungal PCR $(n=70)$} & \multirow{3}{*}{$\begin{array}{c}\text { Sensitivity } \\
\%\end{array}$} & \multirow{3}{*}{$\frac{\text { Specificity }}{\%}$} & \multirow{3}{*}{$\begin{array}{c}\text { Accuracy } \\
\%\end{array}$} & \multirow{3}{*}{$\frac{\text { PPV }}{\%}$} & \multirow{3}{*}{$\frac{\text { NPV }}{\%}$} \\
\hline & \multicolumn{2}{|c|}{ +ve } & \multicolumn{2}{|c|}{-ve } & \multicolumn{2}{|c|}{ Total } & & & & & \\
\hline & No & $\%$ & No & $\%$ & No & $\%$ & & & & & \\
\hline+ ve & 19 & 27.1 & 0 & 0 & 19 & 27.1 & & & & & \\
\hline -ve & 13 & 18.6 & 38 & 54.3 & 51 & 72.9 & 100 & 74.5 & 81.4 & 59.4 & 100 \\
\hline Total & 32 & 45.7 & 38 & 54.3 & 70 & 100 & & & & & \\
\hline
\end{tabular}

Kappa-Value $=0.613$

$\%$ Agreement $=81.4 \%$

$\mathbf{P}-$ Value $=0.001 ; \mathbf{P}<0.05$ : significant; $\mathbf{P}<0.01$ : highly significant.

Kappa-Value: Strength of agreement Poor $<0.2$ Fair: 0.2-0.4 Moderate: 0.41-0.6 Good: 0.61-0.8 Very good: 0.81-1.0.

Table 4. Serum 1, 3-p-D-glucan by ELISA in comparison to PCR $(n=70)$

\begin{tabular}{|c|c|c|c|c|c|c|c|c|c|c|c|}
\hline \multirow{3}{*}{$\begin{array}{c}\text { Pan-fungal PCR } \\
(\mathrm{n}=70)\end{array}$} & \multicolumn{6}{|c|}{ ELISA $(n=70)$} & \multirow{3}{*}{$\frac{\text { Sensitivity }}{\%}$} & \multirow{3}{*}{$\frac{\text { Specificity }}{\%}$} & \multirow{3}{*}{$\begin{array}{c}\text { Accuracy } \\
\%\end{array}$} & \multirow{3}{*}{$\begin{array}{r}\text { PPV } \\
\%\end{array}$} & \multirow{3}{*}{$\frac{\mathrm{NPV}}{\%}$} \\
\hline & \multicolumn{2}{|c|}{$+\mathrm{ve}$} & \multicolumn{2}{|c|}{$-\mathrm{ve}$} & \multicolumn{2}{|c|}{ Total } & & & & & \\
\hline & No & $\%$ & No & $\%$ & No & $\%$ & & & & & \\
\hline$+v e$ & 23 & 32.9 & 9 & 12.8 & 32 & 45.7 & & & & & \\
\hline$-v e$ & 13 & 18.6 & 25 & 35.7 & 38 & 54.3 & 76.7 & 65.8 & 70.6 & 63.9 & 78.1 \\
\hline Total & 36 & 51.5 & 34 & 48.5 & 70 & 100 & & & & & \\
\hline
\end{tabular}

Kappa-Value $=0.373$

$\%$ Agreement $=68.6 \%$

$\mathbf{P}-$ Value $=0.003 ; \mathbf{P}<0.05$ : significant $\mathbf{P}<0.01$ : highly significant.

Kappa-Value: Strength of agreement Poor $<0.2$ Fair: 0.2-0.4 Moderate: 0.41-0.6 Good: 0.61-0.8 Very good: 0.81-1.0.

Table 2 shows the evaluation of Serum 1, 3- $\beta$-D-glucan by ELISA in comparison to blood culture in diagnosis of systemic fungal infection. ELISA revealed $89.5 \%$ sensitivity, $62.8 \%$ specificity and $70 \%$ accuracy with higher NPV (94.1\%) than PPV (47.2\%). There was a moderate agreement between the two techniques in the diagnosis of systemic fungal infection as regard percentage of total positive and negative cases $(\mathrm{Kappa}=0.41, \%$ Agreement $=70 \%$, P-Value $=0.001)$.

Table 3 shows the evaluation of pan-fungal PCR in comparison to blood culture in diagnosis of systemic fungal infection. Pan-fungal PCR revealed 100\% sensitivity, $74.5 \%$ specificity and $81.4 \%$ accuracy with higher NPV (100\%) than PPV (59.4\%). There was a good agreement between the two techniques in the diagnosis of systemic fungal infection as regard percentage of total positive and negative cases (Kappa $=0.613$, \% Agreement $=81.4 \%$, P-Value $=0.001)$.

In Table 4, Pan-fungal PCR revealed $76.7 \%$ sensitivity, $65.8 \%$ specificity and $70.6 \%$ accuracy with higher NPV (78.1\%) than PPV (63.9\%). There was a fair agreement between the two techniques in the diagnosis of systemic fungal infection as regard percentage of total positive and negative cases $(\mathrm{Kappa}=0.373, \%$ Agreement $=68.6 \%$, $\mathrm{P}$-Value $=0.003)$.

\section{Discussion}

Systemic fungal infection constitutes a serious threat to an ever-growing population of immunocompromised individuals. Establishing a definite diagnosis of systemic fungal infection in cancer patients is difficult and timeconsuming, as delayed initiation of antifungal treatment increases mortality [6]. Blood culture remains the gold standard method for diagnosis of systemic fungal infection although; the sensitivity of blood culture is controversial. This could be attributed to the inability of culture to detect dead organisms and the need for multiple or repeated blood cultures to increase the likelihood of detecting fungemia [6].

The results obtained by blood culture, Ag detection and PCR were coincident with a similar work of Azab et al. in which a greater number of patients with systemic fungal 
infection were identified by both ELISA and pan-fungal PCR than blood culture, with a statistically significant difference [7].

In Table 2, ELISA revealed $89.5 \%$ sensitivity, $62.8 \%$ specificity and 70\% accuracy with higher NPV (94.1\%) than PPV (47.2\%) compared to the gold standard blood culture. Similarly, Ramos et al. found that the sensitivity of ELISA for BDG in relation to culture was $75 \%$ and specificity of $65 \%$ with higher NPV (97\%) than PPV (14.0\%) [8]. Avni et al. also found that the BDG were more sensitive (62\%) as compared to blood culture (17\%) [9].

Serum 1,3 $\beta$-D-glucan (BDG) can be detected in systemic fungal infections as a cell wall component of many pathogenic fungi. It was included as a mycological criterion in the EORTC/MSG consensus group criteria of systemic fungal infection [10]. False-positive BDG results contributing to low test specificity can be attributed to Candida colonization, systemic bacterial infections, antibiotics and cellulose membranes used during hemodialysis [11].

In Table 3, the evaluation of pan-fungal PCR to the gold standard blood culture for diagnosis of systemic fungal infection, pan-fungal PCR revealed $100 \%$ sensitivity, $74.5 \%$ specificity and $81.4 \%$ accuracy with higher NPV (100\%) than PPV (59.4\%).

In a study by Nguyen et al. serum 1,3- $\beta$-D-glucan and PCR results were both significantly more sensitive than blood culture (62\% and $88 \%$ vs. $17 \%$ ) [12]. Ramos et al also reported that the sensitivity and specificity of the PCR performed on blood/serum samples were $87.5 \%$ and $81.6 \%$, respectively. The PPV was $26.9 \%$, whereas the NPV was $98.8 \%$ [8].

There are several potential reasons for the high sensitivity of BDG and PCR assays. For pan-fungal PCR, the use of primers specific for the internal transcribed spacer (ITS1, ITS4) facilitates the detection of lower fungal inoculum in the blood. Also, the detection of circulating free fungal DNA by PCR does not need viable cells, unlike in culture. Likewise, BDG detection is not dependent on viable organisms [12].

One of the more important findings of our study is the high NPV of the PCR (100\%), which might allow ruling out the possibility of fungal infection, withdrawal of unnecessary antifungal therapy, thus reducing any potential toxicity and costs.

Another important advantage of pan-fungal PCR is the possibility of identifying several species of Candida species [13]. Conversely, the amplification of contaminating fungal nucleic acids present in the environment or the laboratory can be a drawback resulting in low test specificity [7].

As illustrated in Table 4, Pan-fungal PCR revealed $76.7 \%$ sensitivity, $65.8 \%$ specificity and $70.6 \%$ accuracy with higher NPV (78.1\%) than PPV (63.9\%). These results are compatible with a previously published study by Nguyen et al. which demonstrated that PCR was more sensitive than BDG in diagnosing systemic fungal infection ( $80 \%$ vs $56 \%$ ), with comparable specificity $(70 \%$ vs $73 \%)$ [12].

In Table 2 - Table 4, the diagnosis of patients with systemic fungal infection revealed a moderate agreement of $70 \%(\mathrm{Kappa}=0.41)$ between ELISA and blood culture.
Additionally, there was a good agreement of $81.4 \%$ $(\mathrm{Kappa}=0.613)$ between the pan-fungal PCR and blood culture and fair agreement $68.6 \%(\mathrm{Kappa}=0.373)$ between ELISA and pan-fungal PCR as regard percentage of total positive and negative cases.

In accordance with our results, a study by Azab et al. detected a moderate agreement between the blood culture and ELISA $69.6 \%(\mathrm{Kappa}=0.43)$, and fair agreement between PCR and blood culture 63.1\% $(\mathrm{Kappa}=0.34)$ [7].

\section{Conclusion}

Rapid diagnostic techniques such as ELISA and PCR offer an accurate and reproducible tool with higher sensitivity and specificity for the diagnosis of systemic fungal infection compared to the gold standard blood culture. The adoption of these techniques can minimize the toxicity caused by empirical antifungal drugs in patients at risk.

\section{Statement of Competing Interests}

Authors declare that there are no competing interests.

\section{References}

[1] Falci DR, Stadnik CM, Pasqualotto AC. A review of diagnostic methods for invasive fungal diseases: challenges and perspectives. Infectious diseases and therapy. 2017; 6(2): 213-223.

[2] Ruhnke M, Böhme A, Buchheidt D, et al. Diagnosis of invasive fungal infections in hematology and oncology--guidelines from the Infectious Diseases Working Party in Haematology and Oncology of the German Society for Haematology and Oncology (AGIHO). Annals of oncology: official journal of the European Society for Medical Oncology. 2012; 23(4): 823-833.

[3] Ruhnke M, Schwartz S. Recent developments in the management of invasive fungal infections in patients with oncohematological diseases. Therapeutic advances in hematology. 2016 Dec; 7(6): 345-359.

[4] Cuenca-Estrella M, Bernal-Martinez L, Buitrago MJ, et al. Update on the epidemiology and diagnosis of invasive fungal infection. International Journal of Antimicrobial Agents. 2008 2008/11/01/; 32: S143-S147.

[5] Ramanan P, Wengenack NL, Theel ES. Laboratory Diagnostics for Fungal Infections: A Review of Current and Future Diagnostic Assays. Clinics in Chest Medicine. 2017; 38(3): 535-554.

[6] Arvanitis M, Anagnostou T, Fuchs BB, et al. Molecular and nonmolecular diagnostic methods for invasive fungal infections. Clin Microbiol Rev. 2014 Jul; 27(3): 490-526.

[7] Azab MM, Abo Taleb A, Mohamed NA, et al. Rapid diagnosis of invasive fungal infections. Int J Curr Microbiol App Sci. 2015; 4: 470-486.

[8] Ramos JT, Villar S, Bouza E, et al. Performance of a Quantitative PCR-Based Assay and Beta-d-Glucan Detection for Diagnosis of Invasive Candidiasis in Very-Low-Birth-Weight Preterm Neonatal Patients (CANDINEO Study). Journal of Clinical Microbiology. 2017; 55(9): 2752-2764.

[9] Avni T, Leibovici L, Paul M. PCR diagnosis of invasive candidiasis: systematic review and meta-analysis. Journal of clinical microbiology. 2011; 49(2): 665-670.

[10] De Pauw B, Walsh TJ, Donnelly JP, et al. Revised Definitions of Invasive Fungal Disease from the European Organization for Research and Treatment of Cancer/Invasive Fungal Infections Cooperative Group and the National Institute of Allergy and Infectious Diseases Mycoses Study Group (EORTC/MSG) Consensus Group. Clinical Infectious Diseases. 2008; 46(12): 1813-1821. 
[11] Alexander BD, Smith PB, Davis RD, et al. The $(1,3) \beta$-D-glucan test as an aid to early diagnosis of invasive fungal infections following lung transplantation. Journal of clinical microbiology. 2010; 48(11): 4083-4088.

[12] Nguyen MH, Wissel MC, Shields RK, et al. Performance of Candida Real-time Polymerase Chain Reaction, $\beta$-D-Glucan
Assay, and Blood Cultures in the Diagnosis of Invasive Candidiasis. Clinical Infectious Diseases. 2012; 54(9): 1240-1248.

[13] Wagner K, Springer B, Pires VP, et al. Molecular detection of fungal pathogens in clinical specimens by $18 \mathrm{~S}$ rDNA highthroughput screening in comparison to ITS PCR and culture. Scientific Reports. 2018 2018/05/03; 8(1): 6964.

(C) The Author(s) 2019. This article is an open access article distributed under the terms and conditions of the Creative Commons Attribution (CC BY) license (http://creativecommons.org/licenses/by/4.0/). 